Journal of Research in Interprofessional

Practice and

Education

Vol. 9.1

2019

a. The Swedish Red Cross University College, Dept of Health and

Science, Stockholm, Sweden.

Karolinska Institutet Department of Learning, Informatics and

Ethics, Stockholm, Sweden

b. KTH Royal Institute of Technology, School of Engineering Sciences in Chemistry, Biotechnology and Health, Department of Biomedical Engineering and Health Systems

Journal of Research in Interprofessional Practice and Education (JRIPE)

Vol. 9.1

(c) 2019

doi: 10.22230/jipe.2019 v9n1a275

Corresponding author: Janet Mattsson. Email: matj@rkh.se.

\section{Interprofessional Learning for Enhanced Patient Safety: Biomedical Engineering Students and Nursing Students in Joint Learning Activities}

\author{
Janet Mattsson ${ }^{\mathrm{a}}$, RN, PhD; Britt Östlund ${ }^{\mathrm{b}}$, PhD; \\ Gunilla Björling ${ }^{c}$, RN, PhD; Anna Williamsson ${ }^{b}, \mathrm{PhD}$; \\ \& Andrea Eriksson ${ }^{\mathrm{b}}, \mathrm{PhD}$
}

\begin{abstract}
Background: In the last decade, research has highlighted the importance of interprofessional approaches to education and practice. Collaboration between medical practice and engineering has been identified as particularly relevant to developing accountable models for sustainable healthcare and overcoming increased specialization leading to professional barriers. This study aims to analyze insights and understanding expressed by nursing students and biomedical engineering students following a joint learning activity regarding a medical device used in the hospital setting.

Method: A qualitative approach deriving from a phenomenological view examined an interprofessional learning activity where the focus was on active integration and knowledge exchange.

Conclusion: The activity was expressed as a positive opportunity for getting insights into perspectives from other professional groups as well as insights into the importance of a system perspective in patient safety. The learning and insights listed in the evaluations included ideas about how the two professional groups could collaborate in the future.
\end{abstract}

Keywords Patient safety; Joint learning; Biomedical engineering

\section{Introduction}

In the last decade, research has highlighted the importance of interprofessional approaches to education and practice $[1,2]$. Collaboration between medical practice and engineering has been identified as particularly relevant to developing accountable models for sustainable healthcare and to overcoming increased specialization leading to professional barriers, including professional jargon, problem-solving and approaches, and conflicting values [3,4,5]. Many of these barriers have been learned and internalized during education, which leads to a demand for different learning opportunities [6]. In the field of medical practice and engineering, there is a call for a more holistic collaboration, breaking out from a system of traditional isolated learning "silos" to get a more authentic connection to the healthcare practice, as practice is becoming increasingly complex $[6,7,8]$. One aspect of overcoming silos is about who should collaborate in making technology work. 
2

Joint Learning for Enhanced Patient Safety

Mattsson, Östlund, Björling, Williamsson, \& Eriksson

c. The Swedish Red Cross University College, Dept of Health and Science, Stockholm, Sweden. Karolinska Institutet, Dept of Clinical Sciences, Danderyd Hospital, Stockholm, Sweden

Journal of Research in Interprofessional Practice and Education

Vol. 9.1

2019
When medical practice and engineering are discussed, it is usually limited to physicians and engineers. Healthcare professionals such as nurses and assistant nurses are rarely in focus [9], even though nurses are the ones working hands-on with the technical devices on a daily basis while caring for patients. Physicians often delegate responsibility in clinical trials to nurses and more and more nurses have research skills, yet there is a lack of knowledge about how to organize and perform joint learning activities that include nurses and engineers. Nurses and biomedical engineers both affect patient safety [8] and are both directly involved in patient safety activities, such as calibrating technical devices, adjusting levels of pressure in infusion pumps, but there is little awareness of how biomedical engineering students and nursing students could train together. About 100,000 adult patients suffer from injuries every year in somatic hospital care in Sweden, and up to 100 of those patients lose their lives [10]. The most common of these injuries, 34 percent of them, are healthcare-related infections, 21 percent are maternal injuries, blood clots, or skin injuries, 13 percent are surgical injuries, and 10 percent are drug-related injuries. In particular, there is a lack of understanding of the nurses' role when enhancing patient safety.

Unlike the physician, who is responsible for the diagnosis and prescribing treatments and drugs, the nurse is responsible for the caring situation, how the patient is positioned, how medications are delivered or when interventions are appropriate. Nurses are making observations, following every detail of the patient's needs and providing relevant and sufficient care. Engineers provide technological support for monitoring the course of the disease. In a critical situation, where technology fails or the patient status changes in an unexpected way, engineers immediately start to search for technological problems; nurses, on the other hand, immediately direct their attention to the patient. They both act according to their different educational training and competencies, but they attend to the same patient in the same situation.

This challenge is also apparent when it comes to digitalization and the implementation of medical devices in areas outside hospitals: in homes and for people on the move. The shift in attention from a focus on technology with a single application and from a focus on individual patients as passive receivers of care to offering person-centred care makes healthcare professionals and engineers more dependent on each other. Joint learning will be increasingly important to facilitate teamwork and patient care, not least opportunities for exposure to real-life situations or learning opportunities that relate directly to the caring context [11]. It can be assumed that both the interaction and communication between the two professions becomes a vital factor that influences the outcome of critical situations and the patient's wellness. With this development, the caring context, as well as the system in which caring and technology interact, becomes an essential aspect of healthcare education as well as engineering education.

\section{The aim of the study}

This study aims to analyze insights and understanding expressed by nursing students and biomedical engineering students following a joint learning activity regard- 
3

Joint Learning for Enhanced Patient Safety

Mattsson, Östlund, Björling, Williamsson, \& Eriksson

Journal of Research in Interprofessional Practice and Education

Vol. 9.1

2019 ing a medical device used in the hospital setting, and patient safety. Further, the study aims at enhancing the knowledge of how specific interprofessional learning activities can contribute to a broadened, shared understanding among participating students concerning patient safety and the quality of care.

\section{Theory}

\section{Interprofessional learning}

Different educational focuses can contribute to narrow approaches to patient care among different groups of healthcare professionals $[12,13]$. One way of stimulating students to reach a higher cognitive level is to introduce a collaborative task. The education of nursing students is traditionally focused on building the students' capacity for offering high-quality care to an individual patient. On the other hand, the education of biomedical engineering students is commonly focused on building the students' capacity in developing advanced medical technology. The World Health Organization (WHO) states that future demands on healthcare worldwide will involve collaborative practice and its integration in education policies [14]. Research shows that the lack of practicing context can cause the protectiveness of professional roles or misunderstanding in the team [15]. An important factor of delivering highquality care and a safe patient environment is communication and collaboration within the healthcare team [16]. This article is thus focusing on how interprofessional learning activities may give nursing and biomedical engineering students broader insights into their future practicing context. Interprofessional learning activities based on a system approach may facilitate students' insights into critical conditions for a safe patient environment. According to system theory, the practicing context of healthcare can be described by four key subsystems: 1) organizing arrangements, 2) social factors, 3) technology, and 4) physical settings [17].

Organizing arrangements are defined by the existing regulations and procedures for patient care. Social factors include interactions between healthcare professionals and the leadership style of a healthcare manager. Technology includes the applications of medical devices in healthcare. Finally, the physical settings include the interior design of a patient ward [17]. Porras's and Robertson's system theory [17] has been widely used in both research and practice for analyzing how, for example, accidents may occur following specific interactions between the "human," the "technology," and the "organization" (HTO) in a working system [18,19]. An HTO analysis may give insights on how organizational factors impact human cognitive decision processes, such as stress, and how technology can be designed to take into account human and/or organizational conditions. A learning activity based on HTO analysis may thus facilitate students' insights into how complex and interrelated factors in different subsystems affect patient safety. Furthermore, reflections in interprofessional student groups within the learning activity may give insights into specific parts of the subsystem that one professional group might have gained less knowledge in from their professional education and experiences. In other words, HTO analysis means to analyze processes, activities, and interactions from both an individual and a systems perspective. A collaborative learning activity may contribute to 
4

Joint Learning for Enhanced Patient Safety

Mattsson, Östlund, Björling, Williamsson, \& Eriksson

Journal of Research in Interprofessional Practice and Education

Vol. 9.1

2019 biomedical engineering students gaining insights into the importance of developing technology that is adapted to healthcare professionals' practicing context. Nursing students may simultaneously gain insights concerning the essential aspects of their practicing context, including interactions between organizational conditions, the use of medical devices, and patient safety.

\section{Learning perspectives}

As a result of the Bologna Process [20,21], new legal directives have been adopted in Sweden highlighting the necessity of the outcome-based education (OBE) Higher Education Act and the Higher Education Ordinance [22]. A key to OBE is that the focus of learning shifts from teacher-centred learning to student-centred learning; teachers distance themselves from transferring knowledge and instead focus on OBE when they design learning activities. The learning perspective raises the importance of student learning through active participation, as students develop understanding through activity. It is the role of the teacher to provide these opportunities. By doing so, the students become engaged in a reflective exercise aiming to encourage cognitive development [23]. The context of learning provided by the teacher, and what the student contributes to the learning situation, will depend on what knowledge is being constructed and which prerequisites are an essential basis for building new knowledge. New knowledge leads to a conceptual change, where students can apply their knowledge to new situations. A challenge is how the teacher can define tasks aimed at a cognitive level appropriate for the student or how development to a higher level is supported. A student learning perspective encompasses both interprofessional learning and a system perspective on learning. To close the gap of knowledge about interprofessional education and training for biomedical engineering students and nursing students, the Swedish Red Cross University College (SRCUC) and the Royal Institute of Technology (KTH) organized a joint learning activity about the design and practice of medical technology in hospital healthcare. More specifically, a joint workshop was designed, highlighting the increasing complexity of technological systems in healthcare and the growing awareness of patient safety.

\section{Methodology}

This study included an interprofessional learning activity for nursing and biomedical engineering students where the focus was on active integration and knowledge exchange [24]. This interprofessional learning task also provided a better understanding of the boundaries of the students' future occupations and collaboration needs within the healthcare setting after graduation. The learning activities and expected outcomes were communicated to the students, and there was a constructive alignment throughout the learning activity [25]. In the activity, the students became responsible for collective learning, not simply individual learning [26]. The learning activity was designed to both promote deep learning and to be meaningful to the students. The tasks were based on an authentic situation that had occurred with nursing and technology. It was also a situation that can happen again, which made it meaningful to discuss and try to solve jointly. The joint workshop was 
5

Joint Learning for Enhanced Patient Safety

Mattsson, Östlund, Björling, Williamsson, \& Eriksson

Journal of Research in Interprofessional Practice and Education

Vol. 9.1

2019 arranged so that nursing students and biomedical engineering students discussed a reported clinical case of one patient's death during post-caring-observation after heart surgery in an intensive care unit [18]. The report of the clinical case was based on an investigation that was initiated with the assumption that the death was caused due to technical failures. The investigation, however, showed that mistakes from nursing professionals and engineering professionals in relation to patient care in connection with monitoring, poor premises design, and mental stress due to unclear procedures and high workload caused poor patient safety and contributed to the death [18]. In other words the investigation pointed at how the interactions between human, technical, and organizational factors contributed to the accident.

The learning activities were designed so that students were able to achieve the skills and knowledge set out in the curriculum's intended learning outcomes. This meant that the learning activities in the workshop were developed for supporting the student's HTO analysis of factors contributing to the accident from a co-worker perspective as well as a managerial perspective.

\section{The participants}

Biomedical engineering students from the School of Technology and Health at KTH participated in the workshop as part of Ergonomics and Sustainability, a mandatory course given in the third year of a five-year civil engineering education (Master's program) in biomedical engineering. Nursing students in their final semester of a three-year bachelor program at the SRCUC participated in the workshop with the engineering students. The workshop was mandatory and covered patient-safety aspects from an organizational perspective, technical perspective, and nursing perspective. Fifty-nine students participated in the workshop in 2016: 39 engineering students (22 women and 17 men) and 20 nursing students. In 2017, 69 students participated: 39 engineering students and 33 nursing students.

The organization of the joint learning activity

The aim of the joint learning activity was: Nursing students and engineering student shall jointly discuss, analyze, and summarize the subsystems and factors in the HTO system described in the report that is of importance for sustainable healthcare and work life for healthcare staff.

The students prepared by reading the investigation's report on how healthcare professionals and different workplace incidents potentially contributed to the patient's death. The engineering students wrote individually prepared assignments where they identified problems in the HTO interaction at the hospital where the death took place. All students were organized in mixed groups with at least two engineering students and two nursing students per group. Each group worked with two sets of questions during two discussion sessions. Discussions and questions were to be answered by details in the report, the students' own understandings, and the course literature. Questions in the first session were asked from a co-worker perspective and questions in the second session were asked from a managerial perspective (see Table 1). The questions in the two sessions were developed to cover students' reflections and analysis of how aspects of all four critical subsystems in an 
6

Joint Learning for Enhanced Patient Safety

Mattsson, Östlund, Björling, Williamsson, \& Eriksson
Journal of Research in Interprofessional Practice and Education

Vol. 9.1

2019
HTO system-i.e., aspects of organizing arrangements, social factors, technology, and physical settings [17] — contributed to the accident. More specifically, the questions encouraged the students in the mixed groups to explore their different reflections and perspectives on how the physical work environment, psychosocial factors, cognitive processes, professional role clarity, technical design, organizational routines for patient safety, leadership responsibilities, and organizational pre-conditions might have contributed to the accident.

Table 1. Questions used for discussion sessions during the workshops

\begin{tabular}{|l|l|}
\hline Co-worker perspective & Managerial perspective \\
\hline - The cognitive load on staff & • Responsibilities for different levels of managers \\
- The psychosocial work environment with a focus on & concerning work environment and patient safety \\
control, demand, and support & - Operative managers' desirable leadership qualities \\
- Responsibility as a co-worker for the work & for a sustainable HTO system \\
environment & - Examples of managerial priorities in routines for \\
• Faults and failures in the use of medical technology & improved patient safety \\
- Other technology or aids used in communication & - Examples of priorities in the legislated work- \\
and/or collaboration & environment management system to deal with \\
-The use and meaning of reporting adverse events & work-environment issues \\
& • Possible organizational conditions affecting the \\
& deadly outcome \\
\hline
\end{tabular}

Further questions included the students' suggestions for measures for developing an HTO system where risks of incidents are minimized. In summary, the assignments aimed at helping the development of practical skills as well as cognitive abilities [27] to approach the use of medical devices from a system perspective. An underlying idea of the implementation of analysis and reflections in mixed groups was that when students from two different fields come together, they could be viewed as representing two different communities of practice with different languages, culture, priorities, and understanding of work practice [28]. The interaction through the learning activity was designed to uncover different perspectives and give an opportunity for both student groups to reflect on how the respective professional groups' communities of practice differ and how they inform professional actions and decisions. These kinds of reflections were included with the aim of developing students' understanding of their future professional identity [28,29].

After each discussion session, a joint discussion was held with the whole class and attending teachers from the SRCUC and the KTH. After both the smaller and the whole-class discussions, all students were given time to sum up their experiences in an anonymous feedback letter, which was given to the teachers.

\section{Data collection}

At both workshops, all students were asked to voluntarily hand in an anonymously written reflection, the feedback letter, about the joint workshop. They were asked to evaluate the activity by responding to three questions: 1 . What are your views on 
7

Joint Learning for Enhanced Patient Safety

Mattsson, Östlund, Björling, Williamsson, \& Eriksson
Journal of Research in Interprofessional Practice and Education Vol. 9.1 2019 patient safety after today's workshop? 2. What are your views on collaboration between biomedical engineers and nurses after today's workshop? 3. What did you learn from today's workshop? All students handed in their evaluations.

\section{Analysis}

According to Benner et al. [30], analysis begins in conjunction with data collection. In this study, we started by reading the evaluations from the first workshop in 2016 to get an understanding of the learning activity as a whole. Was it meaningful to the students? The evaluations were read and reread several times and found to describe the workshop as meaningful in diverse ways. We decided to continue with the next class of students. We read the written evaluations collected in 2017, and then the evaluations from the two groups were put together and read as a whole. The authors, Andrea Eriksson and Janet Mattsson, first read and reread the material separately to get a notion of what it was all about. In the next phase, they each sought paradigm cases and exemplars. Paradigm cases can be viewed as evaluations that differ distinctly from the others; they become the foreground [30]. Evaluations that represent the predominant view are called exemplars; paradigm cases are mirrored back on them to get a notion of the whole. This gives analyses depth and variety. Then the authors jointly discussed which evaluations were exemplars and which were paradigm cases. They compared their analysis and decided jointly if there was a discrepancy. Using the hermeneutic circle, exemplars became a foundation that deepened or explained the meaning of the paradigm cases. This joint interpretation added a deeper understanding of students' concerns, conflicts, and choices [30,31]. Parts of the text that were interpreted as salient to the aim of the study were highlighted and given descriptive names (Benner et al., 2009; Brykczynski \& Benner, 2010). In the next phase, the authors discussed the meaning that the various names captured. The re-naming in this phase aimed to elucidate the patterns of meaning in the learning activity [30].

\section{Ethical considerations}

Ethical guidelines according to Swedish law [32] were followed, and program directors granted approval to conduct interviews. No personal information, or other sensitive information, about the students was collected. All students participating in the learning activity gave their informed consent. All data were collected confidentially, and it was not possible to identify any of the students during analysis. All students were informed that they could withdraw their participation in the study if they wished, whenever they wanted.

\section{Results}

An overall summary of the students' evaluations shows that a majority of their evaluations were positive assessments of the learning activity that took place at the workshop. The positive appraisals of the seminar were underlined by statements such as "educational," "interesting," "fun," "cool," "fascinating," "useful insights," and "relevant." Only a few students assessed the learning activity as less meaningful, including opinions that the students from the different professional groups did not 
8

Joint Learning for Enhanced Patient Safety

Mattsson, Östlund, Björling, Williamsson, \& Eriksson

Journal of Research in Interprofessional Practice and Education

Vol. 9.1

2019 contribute with different perspectives on the questions discussed, or that the learning activity mainly meant that nursing students had to explain how things function in healthcare to engineering students. In summary, the activity was expressed as a positive opportunity for gaining insights into perspectives from other professional groups, as well as insights into the importance of a system perspective in regards to patient safety. The learning and insights listed in the evaluations included ideas about how the two professional groups could collaborate in the future. These insights were promoted by obtaining clarifications of the knowledge/perspectives representing the other professional group through the learning activity. By getting perspectives from the work situation of the end users, engineering students described insights on what to think about when designing medical devices. Nursing students, on the other hand, mentioned insights on how engineers think when designing medical devices. "This gives hope for opportunities for future solutions," one nurse stated. "You get insight into other professionals' mind sets and [put] faces on the people behind the machines," commented another nurse.

\section{Insight and understanding gained by mutually seeking answers to common questions}

The discussions and the exchange of experiences were described to give insights based on perspectives from both professional groups. An understanding developed through dialogue. Looking at the same topic from different angles offered the possibility to learn with and from each other. Engineering students pointed out things they had not thought of by themselves, but that nursing students took for granted. Nursing students thought that it was valuable to reflect on their perspectives and stated that the learning activity gave them insight into flaws in their perspectives. Participants expressed that the learning activity illuminated their own knowledge gaps and revealed areas where there was a need to complement their knowledge. This is highlighted in the following quote: "Yes, the seminar was meaningful as knowledge could be exchanged and [we could] come together to answer from two different perspectives."

The positive experience of the learning activity encouraged the students to document their insight on the feedback forms following the seminar. This was especially notable in the engineering students' assessments of the course evaluations. The engineering students stressed the value of listening to nursing students explaining their future working conditions. It gave the engineering students insight into how the physical work environment and cognitive load on healthcare professionals affect patient safety. This seemed to inspire some engineering students to develop work that will positively influence working conditions for nurses. "It was very interesting to hear 'the other side,' how the users experience the devices," one commented. Exploring answers to common questions was also described as illuminating different opinions and communication problems related to industry-specific jargon.

The discussions between the interprofessional student groups were thought to facilitate a deeper understanding and illuminate a wider variety of aspects than they would have in homogenous student groups. The discussions in the cross-groups 
9

Joint Learning for Enhanced Patient Safety

Mattsson, Östlund, Björling, Williamsson, \& Eriksson

Journal of Research in Interprofessional Practice and Education

Vol. 9.1

2019 contributed to more thoughtful solutions-the engineering students brought technical knowledge and the nursing students brought practical knowledge on how "things work" in healthcare. However, a few students thought that the questions in the seminar were too controlling and that the learning activity would have gained from discussions that were more open.

The students' assessments of the knowledge contribution following the learning activity can be summarized as a change of understanding of how technology and nursing are connected and a deepened understanding of the importance of considering pre-conditions, perspectives, and the knowledge of other professional groups for improving patient safety. Students got insight into the importance of how the two professional groups are collaborating in the clinic to enhance patient safety; it was concretized as the need for collaborating in the early stages of developing medical devices. "It was good to get the opportunity to reflect upon our perspective and see what possible improvement we can contribute to in the future," stated one participant. "Being an engineering student, you don't learn that much about what is going on out there in the hospital wards," said another. "Nurses don't talk so much about technological devices even though this is part of our daily work," reported a nursing student.

\section{Understanding HTO-system perspectives on patient safety}

Discussions based on the case were experienced as a useful method for learning from previous mistakes. The real-life case and the HTO questions related to the case were described to facilitate insights on patient safety from a systems perspective; the case was well chosen for getting a grip on interactions between HTO. Following the learning activity, many of the students reported gaining knowledge on the interactions between HTO and a better understanding of the complexity of healthcare. For example, a change in understanding how interactions between nurses and technology affect patient care was voiced, and it was described as a lesson about how to analyze the causes of patient-safety problems from a system perspective. Several participants expressed an understanding of the importance of collaboration between the two professional groups for improving healthcare and patient safety. "Good cooperation and good communication between different professionals are necessary to promote HTO-perspectives. Badly designed products can lead to stress and that it is wrongly used, which will lead to severe consequences," stated one participant.

The importance of leadership and the work environment

Nursing students' experiences were recounted to help engineering students understand the complexity of healthcare. This was perceived as an efficient way of giving engineering students a better overview of the problems in healthcare. Subsequently, many of the students expressed insights on organizational structures and leadership within healthcare. Engineering students experienced new insight into how the work environment and mental health of healthcare professionals affect patient safety. Engineering students expressed that they had no previous experience in healthcare, and that they learned a lot from actually hearing how things work in practice; they embraced a better understanding of nursing following the seminar. They also 
10

Joint Learning for Enhanced Patient Safety

Mattsson, Östlund, Björling, Williamsson, \& Eriksson
Journal of Research in Interprofessional Practice and Education Vol. 9.1 2019 described learning about the importance of regulations and routines in work, as well as the importance of shared responsibilities among different professional groups for increased patient safety. The importance of not relying blindly on the technology but taking human factors and the work environment into account was also stressed. "As an engineer," said one participant, "I had no idea what heavy workload a nurse has."

\section{The design of technology}

Students representing both professional groups expressed insights into possible improvements for the design and use of medical devices.

Participants, especially the engineering students, recounted learning about the importance of the design of medical devices, including that developing "good" technology is not enough; it is equally important to consider the context and knowledge of the end users when designing medical devices. Some engineering students reported a better understanding of how they impacted the work environment of healthcare professionals, as well as patient safety. Engineering students also noted that nurses might deal with medical devices in other ways than those intended by the designer. This highlighted the importance of testing devices in the context that they are designed for. Engineering students also described an understanding of the importance of focusing on the patient.

Nursing students expressed that the learning activity developed their understanding of how engineers think when they design medical devices. They also expressed insights into having a personal responsibility to understand and stay up to date on medical technology. "It was good to get to know the perspectives of the engineers," said a nursing student, "to understand how their decisions, good or bad, affect practice. Their technological thinking is from another angle than ours."

\section{Suggestions for improvements and future collaboration}

The learning activity was acknowledged for giving ideas on real collaboration between medical engineers and nurses-a collaboration that could potentially contribute to the development of better products and a better working environment. The importance of continuous dialogue between the groups was stressed. Many of the students expressed a wish for increased collaboration between the student groups. A future complementary learning activity where the student groups prepared presentations on the use of medical devices from their perspectives was suggested. To get more reciprocity between the groups, learning activities where engineering students teach and explain to nursing students how medical devices function was suggested. Questions on product development and why medical devices are designed in certain ways were also considered.

\section{Discussion}

This study gave insights into the strengths of interprofessional learning, which could be of importance to future students in achieving collaboration and creating a culture for patient safety. The learning activity's structure of small discussion groups of nursing students and engineering students facilitated opportunities for learning from each other and seemed to contribute to more nuanced discussions on the 
11

Joint Learning for Enhanced Patient Safety

Mattsson, Östlund, Björling, Williamsson, \& Eriksson

Journal of Research in Interprofessional Practice and Education

Vol. 9.1

2019 topic-especially the new insight that developing well-functioning technology will not be enough to enhance patient safety. Throughout the interprofessional learning situation, the notion of the patient was evident in students' discussions. The discussions themselves encouraged working as a team, communicating, and problem-solving, and highlighted students' responsibility to prepare for future situations in the workplace context [33]. During the discussions, the students came to be more familiar with the different occupational jargons, which can be a vital barrier breaker for future collaborative work. Following the learning activity, the engineering students became aware of their limited experiences in the healthcare context, and the nursing students became aware of their limited knowledge about medical devices. As students discuss and interact in different ways, their commitment and confidence might increase [34], which could strengthen them in their future professional roles. For instance, it became clear to the nursing students that they have a responsibility to educate themselves on the technical devices they are about to meet in the clinical context. For the engineering students, it became evident that their design could affect patient safety in the caring situation; the patient perspective became real.

Shortly, the nurses will enter the workforce and have to collaborate and work with technology in a new way. However, their priority must remain on the patient at all times. This will require new ways of collaborating across professions; a learning situation such as this might be the first step to bridge the gap between engineers and nurses. Research [35] shows that increasing awareness and tolerance for different opinions on various issues is an important aspect to consider for their future profession, especially in teamwork. When the students were brought together, it became natural to discuss ethics, which are considered essential for developing professionalism [36]. One reason why the students were predominately positive might be that the learning situation was meaningful to them, and thus opened a new and deepened understanding about their upcoming professional role. After reading the case description for the workshop, the students presented their understandings of what caused what on how the situation unfolded, which primarily enhanced their capabilities to communicate in a clear and stringent manner, which is essential in all professions. As they discussed and got feedback, knowledge gaps between what students have learned and the expected results were uncovered. They could then repeat this discussion process and fill knowledge gaps, thus completing the feedback loop [37,38,39].

Through the learning activity, engagement among students was promoted to contribute to improvements in the healthcare system that influence patient safety and working conditions for healthcare personnel. The students showed a better understanding of the complexity of healthcare following the learning activity. The HTO analysis within the learning activity facilitated the students' insights into how complex and interrelated factors affects working conditions and patient safety $[17,19]$. The learning activity gave the students insights into specific processes, activities, and interactions in the healthcare system that can be improved by increased collaboration between the two professional groups.

The students were confident in general in their evaluations of the learning activities. One explanation can be the novelty effect, which is that meeting another perspec- 
Joint Learning for Enhanced Patient Safety

Mattsson, Östlund, Björling, Williamsson, \& Eriksson

Journal of Research in Interprofessional Practice and Education

Vol. 9.1

2019 tive or unknown professional competence will raise students' attention just by being new. Another explanation is that providing these learning activities fills a need to learn about the situated use of technology in the hospital setting, its effects on patient safety, and what makes it work. Since educations often focus on the individual, this was an opportunity to learn about the systemic conditions of making technology work, and that patient safety is the result of the interactions between patients, medical technologies, and healthcare professionals-especially biomedical engineers and nurses, who are hands-on with the patients and follow the progression of treatments.

This study reveals that nursing students and biomedical engineering students are highly motivated to learn about each other and how they can jointly enhance patient safety. These learning opportunities should be provided as part of their education. The engineering students stressed the value of listening to nursing students explaining their future working conditions, which gave them insight on how the physical work environment and cognitive load on healthcare professionals affect patient safety. Nursing students also expressed insights into their personal responsibility to understand and stay updated on medical technology.

The overall results of the evaluations suggest that engineering students should learn how to explain technology to nursing students and nursing students should explain how they care for patients. How else can they increase their context awareness and learn about restrictions and risks when using medical technologies in practice? To accomplish this, a favourable learning climate is essential. To engage the students in meaningful learning, a formative feedback involved them in ongoing reflection during the workshop. This also uncovered any knowledge gaps between what students have learned and the expected results [40].

The results of this study also suggest the general importance of cross-border learning activities. Increasing awareness and tolerance for different opinions on various issues is an important aspect to consider for future professionals, especially in teamwork. Discussions and reflections on ethics are essential for developing professionalism $[35,36]$.

\section{Conclusions}

This study suggests that joint interprofessional learning activities between nursing students and biomedical engineering students can deepen their understanding of how their interaction in a caring situation that includes patients and medical technology affect patient safety and the quality of care. Furthermore, the study indicates at that an HTO analysis of a real-life case can broaden insights in patient safety. These results highlight the importance of promoting such learning activities within education.

\section{References}

1. Brandt, B.F., Cerra, F.B., \& Delaney, C.W. (2015). The United States Center for Interprofessional Practice and Education: Integrating an informatics approach to interprofessional work. Journal of Interprofessional Education, 29(6) 592-595.

2. Matsuki, N., Takeda, M., Yamano, M., Imai, Y., Ishikawa, T., \& Yamaguchi, T. (2010). Designing clinical education program for engineers: The ESTEEM Project. Journal of Interprofessional Care, 24(6), 738-741. 
13

Joint Learning for Enhanced Patient Safety

Mattsson, Östlund, Björling, Williamsson, \& Eriksson

Journal of Research in Interprofessional Practice and Education

Vol. 9.1

2019
3. Coye, M.J., \& Kell, J. (2006) How hospitals confront new technologies. Health Affairs, 25(1), 163-173.

4. Hall, P. (2005). Interprofessional teamwork: Professional cultures as barriers. Journal of Interprofessional Care, 19(esup1), 188-196.

5. Lazarus, J., Meservey, P.M., Joubert, R., Lawrence, G., Ngobeni, F., \& September, V. (1998). The South African community partnerships: Towards a model for interdisciplinary health personnel education. Journal of Interprofessional Care, 12(3), 279-288.

6. Strobel, J., Hess, J., Pan, R., \& Wachter Morris, C. A. (2013). Empathy and care within engineering: Qualitative perspectives from engineering faculty and practicing engineers. Engineering Studies, 5(2), 137-159.

7. Lazarus, I.R., \& Fell, D. (2011). Innovation or stagnation? Crossing the creativity gap in healthcare. Journal of Healthcare Management, 56(6), 363-367.

8. Ng, E.S. (2011). Bridge over troubled waters: Connecting doctors and engineers. Journal of Interprofessional Care, 25(6), 449-451.

9. Mick, D.J., \& Ackerman, M.H. (2005). Nursing and biomedical engineering transdisciplinary clinical trials collaboration. Medical Devices, 2(2), 131-133.

10. Socialstyrelsen [National Board of Health and Welfare]. (2017). Utvecklingen inom patientsäkerhetsområdet. Report 2017-4-3. URL: http://www.socialstyrelsen.se/Lists/Artikelkatalog /Attachments/20575/2017-4-3.pdf [January 25, 2019].

11. Robertson, J. \& Bandali, K. (2008) Bridging the gap: Enhancing interprofessional education using simulation. Journal of Interprofessional Care, 22(5), 499-508.

12. Miller, P.A. (2001). Nurse-physician collaboration in an intensive care unit. American Journal of Critical Care, 10(5), 341-350.

13. Suter, E., Arndt, J., Arthur, N., Parboosingh, J., Taylor, E., \& Deutschlander, S. (2009). Role understanding and effective communication as core competencies for collaborative practice. Journal of interprofessional care, 23(1), 41-51.

14. World Health Organization. (2010). Framework for action on interprofessional education and collaborative practice (No. WHO/HRH/HPN/10.3). Geneva: World Health Organization.

15. Barnsteiner, J.H., Disch, J.M., Hall, L., Mayer, D., \& Moore, S.M. (2007). Promoting interprofessional education. Nursing Outlook, 55(3), 144-150.

16. Davenport, D.L., Henderson, W.G., Mosca, C. L., Khuri, S.F., \& Mentzer Jr, R.M. (2007). Riskadjusted morbidity in teaching hospitals correlates with reported levels of communication and collaboration on surgical teams but not with scale measures of teamwork climate, safety climate, or working conditions. Journal of the American College of Surgeons, 205(6), 778-784.

17. Porras, J.I., \& Robertson, P.J. (1992). Organizational development: Theory, practice, and research. In Dunnette, M.D. \& Hough, L.M., (Eds.), Handbook of Industrial and Organizational Psychology, (719-822). Palo Alto, CA: Consulting Psychologists Press.

18. Statens haverikommission [Swedish Accident Investigation Authority]. (2013). Slutrapport RO 2013: 02: Dödsfall på hjärtklinikens hjärtintensivavdelning N25 vid Karolinska Universitetssjukhuset $i$ Solna, den 17 oktober 2010. URL: https://www.havkom.se/assets/reports /Swedish/RO-2013_02.pdf [January 25, 2019].

19. Rollenhagen, C. (1995). MTO-en introduktion. Sambandet människa, teknik och organisation. [The connection between human, technology and organisation]. Lund: Studentlitteratur.

20. Christensen, L. (2004). The Bologna Process and medical education. Medical Teacher, 26(7), 625-629.

21. Pleschová, G., Simon, E., Quinlan, K.M., Murphy, J., Roxa, T., \& Szabó, M. (2012). The professionalisation punting of academics in higher education. Science position paper. (É. Franchineau, Ed.), (pp. 1-32). Brussels: European Science Foundation.

22. Swedish Council for Higher Education. (1992). The Swedish Higher Education Act. Swedish Code of Statutes (SFS) No. 1992:1434. URL: https://www.uhr.se/en/start/laws-and-regulations/Lawsand-regulations/The-Swedish-Higher-Education-Act/ [March 27, 2019].

23. Mayer, R.E. (2002). Rote versus meaningful learning. Theory into Practice, 41(4), 226-232.

24. Parsell, G., Spalding, R., \& Bligh, J. (1998). Shared goals, shared learning: evaluation of a multiprofessional course for undergraduate students. Medical education, 32(3), 304-311.

25. Biggs, J. (1999). What the student does: Teaching for enhanced learning. Higher Education Research and Development, 18(1), 57-75.

26. Barr, H. (2013). Enigma variations: Unraveling interprofessional education in time and place. Journal of Interprofessional Care, 27(sup2), 9-13.

27. Grabinger, S., Aplin, C., \& Ponnappa-Brenner, G. (2007). Instructional Design for Sociocultural Learning Environments. E-Journal of Instructional Science and Technology, 10(1), 1-16. URL: http://files.eric.ed.gov/fulltext/EJ846730.pdf [February 27, 2019]. 
Joint Learning for Enhanced Patient Safety

Mattsson, Östlund, Björling, Williamsson, \& Eriksson
28. Wenger, E. (2000). Communities of practice and social learning systems. Organization, 7(2), 225-246.

29. Lave, J., \& Wenger, E. (1991). Situated learning: Legitimate peripheral participation (R. Pea \& J.S. Brown, (Eds.)). Learning in Doing, 95, 111-138. Cambridge University Press.

30. Benner, P.E., Tanner, C.A., \& Chesla, C.A. (2009). Expertise in nursing practice: Caring, clinical judgment, and ethics. Springer Publishing Company.

31. Brykczynski, K.A., \& Benner, P. (2010). The living tradition of interpretive phenomenology. In B. Chan, G., Brykczynska, K., \& Malone, R. et al. (Eds.), Interpretive phenomenology into Healthcare Research, (pp. 113-141). Indianapolis, IN: Sigma Theta Tau International.

32. SFS. (2003). Lag om etikprövning av forskning som avser människor [Law on ethics in relation to research]. URL: https://www.riksdagen.se/sv/dokument-lagar/dokument/svensk-forfattnings samling/lag-2003460-om-etikprovning-av-forskning-som_sfs-2003-460 [January 30, 2016].

33. Dent, J., Harden, R.M., \& Hunt, D. (2017). A practical guide for medical teachers. London, UK: Elsevier health sciences.

34. Fry, H., Ketteridge, S., \& Marshall, S. (Eds.). (2009). A handbook for teaching and learning in higher education: Enhancing academic practice (3rd ed). New York, NY: Routledge.

35. Martimianakis, M.A., Maniate, J.M., \& Hodges, B.D. (2009). Sociological interpretations of professionalism. Medical Education, 43(9), 829-837.

36. Moon, J.A. (1999). Reflection in learning \& professional development: Theory and practice. London, UK: Kogan Page.

37. Boud, D., \& Molloy, E. (2013). Rethinking models of feedback for learning: The challenge of design. Assessment \& Evaluation in Higher Education, 38(6), 698-712.

38. Nicol, D.J., \& Macfarlane-Dick, D. (2006). Formative assessment and self-regulated learning: A model and seven principles of good feedback practice. Studies in Higher Education, 31(2), 199-218.

39. Ramsden, P. (2003). Assessing for understanding. Learning to teach in higher education (2nd ed.) (pp. 176-206). London, UK: RoutledgeFalmer.

40. Biggs, J., \& Tang, C. (2011). Teaching for quality learning at university (4th ed.). Maidenhead, UK: McGraw-Hill Education. 